\title{
MARKET SURVIVAL CONDITIONS UNDER CONSTANT MARKETING MOBILITY
}

\author{
Ljiljana Stošić Mihajlović1, Svetlana Trajković \\ 1,2 Academy of Technical Vocational Studies, Niš \\ stosicmihajlovicljiljana@gmail.com, cecasvtr@yahoo.com
}

\section{Original Scientific Paper doi:10.5937/jouproman8-24280}

\begin{abstract}
In modern conditions, many universities and colleges in the world provide study programs in the field of communications and relations with the target market public. This is because the marketing profession is reputable and provides opportunities for rapid advancement and the pursuit of ambitions that are characteristic of the human race. People doing market research and marketing are optimistic, cheerful, curious, courteous and dedicated people who literally enjoy their jobs. Related to this is their positive attitude towards the media, which stems from their desire to be aware of everything that is happening in the organizations of the world of work, and beyond, in all areas of human activity. This paper is about the conditions of survival in the modern market, with the realization of sustainable competitive advantage, which imply the constant vigilance of the marketing sector.
\end{abstract}

Key words: market, marketing, market communication, advertising

\section{INTRODUCTION}

From the point of view of people who work in communication with the target market public, the market is viewed from two aspects: from the perspective of the users of marketing services and from the angle of the broadcaster, that is, the manufacturer or seller. However, it is indisputable that the marketing sector is not all-powerful in convincing the market to buy goods or use the services of that particular manufacturer or service provider. Manufacturers themselves need to participate in market communication in order to view the product in the right way, with the aim of creating and maintaining a lasting positive image in the minds of consumers regarding the organization and its products. Therefore, it is justifiably considered that any media campaign is basically a real war. This is true even for such a campaign that is sophisticated and expensive. The goal of every market relations specialist and especially the media is to reach every individual in the customer market. Modern technology has ensured that people can start their entrepreneurial business either from home or from the garage (as now world-famous billionaires like Bill Gates did). All you need is to have access basic means of communication, such as telephones and computers with Internet access. But most importantly, not everyone has the right marketing and marketing approach that could read: My product is the best in the world and nothing will stop me from publishing it to everyone. 


\section{WHO NEEDS COMMERCIAL COMMUNICATION?}

Globally, the 1990s were proclaimed years of entrepreneurship. In Serbia, the entire past decade 2010-2020., are the years of entrepreneurship. It seems that the number of newly opened entrepreneurial shops is never higher, that is, everyone opens their shop in order to enter the market, produce and present concepts that will be successful in the market. In this connection, the question is justified: to whom all market communications are needed, we will list some of those who need them. Most often, these are business ideas that are not met every day or are not met en masse. This means, for mass-use products, market communication is crucial.

1. A clinic providing free treatment to the poor or receiving homeless shelters in order to gain greater public support.

2. To the manager of a newly promoted music band with the intention of being recognized by media outlets and promoters and concert organizers.

3. Young and daring designers trying to take their place in the fashion world and among trendsetters.

4. Actors who are hoping to be discovered by casting agents in order to get a role that will launch them among movie stars.

5. The owner of a store in a large shopping mall, where there is a lot of competition, that seeks to attract the attention of customers.

6. An inventor and an innovator who seeks to produce products that use renewable energy sources (eg cars with rechargeable batteries).
7. An organization that fights addiction and drug addiction, which needs greater funding and support from the local community.

8. An entrepreneur who has opened a new cafe and wants permanent customers.

9. A physician specializing in private practice who intends to increase the number of patients who will be offered treatment services.

10. Professors from the academic world, who usually lose contact with the real world and the market, after many years of teaching.

11. A franchisee who seeks to gain a competitive edge over environmental imitators.

12. To a writer who wants to provide a publisher and the broadest readership.

There is one thing in common with them all, which is to think of as a media relations expert. Namely, if they are not able to think like a marketing expert, they will not know how to act or how to behave when something they did not expect comes up. The marketer and marketer must fight and win the battle for the attention of the market and the general public. Experience has shown that valuable and innovative work in one area has a strong impact that is felt in other areas of life - which means that the better you are a marketing expert and the more you interact with the market, the better you will become as a whole. Only internal factors, such as laziness or fear, can interfere with the achievement of market goals. 
Still, Theodore Roosevelt's quotation has to be mentioned so many times: "Who has never been wrong, nobody is doing nothing." business environment and market opportunities.

\section{THE NATURE AND IMPORTANCE OF MEDIA FOR MARKET SUCCESS}

More than half a century ago, Marshall McLaun wrote. "The only medium is the message." Today, in the $21 \mathrm{st}$ century, these words might state that the only medium is the media themselves, which is certainly true, just as it is true that the present human race and civilization is dominated by the media. In fact, after the immediate family, no one has a greater influence on the being of individuals except the media surrounding the consumer. Each of the market participants and consumers is different and unique, but they are all similar in some situations. Precisely, the task of market analysts is to identify common consumer characteristics in order to perform market segmentation, to conduct a media campaign for the target consumer group.

Practically, all media are for-profit organizations that market information to the target public about the products and services of companies.

In order to reach both consumers and investors, in order to reach the public, they must reach the media and rely on the media. It can be said that media relations are an art, even the ability to provide answers before the public knows, it is an art that creates an image, it is controlled by placing the main trump cards that want to be realized without looking like it quite obvious. Therefore, observation is the most important thing in this business, not the "bare" truth itself. The catchphrase that fits this view may read: credibility is being created today, it is not deserving of hard work.

Michael Levin, in his piece "Guerilla PR 2.0" (Levin, M., 2012) cites an eclectic example of a world-renowned beverage maker, saying: "In 1985, the Coca-Cola Company decided to withdraw its trademark from the shelves." cola probably one of the most successful consumer goods in human history because, according to market research, consumers preferred the formula used by its largest competitor, Pepsi Cola. It is thought that adding sugar (so that the Coca-Cola gets a Pepsi-like taste) will be a solution for re-launching the product, ensuring that the brandy is an elite, sacred phenomenon for the twenty-first century and who knows for how long after that.

The problem was that the public wasn't convinced enough that she didn't really like what she thought she liked. Coca-Cola fans are appalled at the fact that they may lose their favorite soft drink. They organized juries, stocked up on 'old Coke' before being pulled out of stores and briefly saddened the lives of Coca-Cola directors and the hint that the formula would be changed." 19

Modern business is characterized by risk and uncertainty, and such an environment is reflected in the decisions made by managers. On the other hand, management consulting is one of the most important management techniques developed over the last fifty years.

\footnotetext{
${ }^{19}$ Levin, M.(2012) Guerrila PR 2.0, Laguna Beograd, pp. 70
} 
The secondary effect of this invention is the rapid development of new frameworks, tools, and techniques for improving operations in a number of companies. Exposure of consulting organizations to varying combinations of business circumstances and experiences of different companies are allowed for the accumulation of valuable knowledge and business experience."20

\section{STEPS IN MARKET RESEARCH}

Market research methods are an invaluable analytical tool for detecting problems and identifying unmet market needs. Specifically, the insight into which products do not contribute to profit or how these products are perceived in public awareness, greatly helps manufacturers and distributors to define their business and especially production policies in order to improve their market position.

Well-designed market research can greatly help in deciding what to do. Some possible strategic actions are:

- entering completely new markets,

- introduction of a new product

- promote the brand

- optimize your marketing campaign

- change the message that was sent to the audience

- adjust the price based on the consumer's market perception

- change the packaging of the product and the way it is displayed in objects

\footnotetext{
${ }^{20}$ JPMNT Vol5, No 3,2017. Vukovic et all. The importance of consulting in contemporary business management, pp.69
}

Otherwise, there are numerous steps in the literature that explain the process of creating and conducting marketing research. Five steps have emerged, as a generally accepted rule for research marketing.

"In the modern world, everything is for sale, starting from goods and services, through ideas and information, to people, as experts in certain jobs. Nothing is out of the market system, and a well-known password that "everyone and everyone has their price", it seems that before, as it is now, it has its full valorization. Why is it so and why are people trying to get everything they have to market, or is this behavior the result of a general race for profit? Perhaps people evolved in their endeavors to get economically as soon as possible and occupy the best market position. In that sense, the fact is that there is really little chance of winning a superior financial position." 21

1. Define the problem and determine the research goals

2. Create a questionnaire as a means of structured communication

3. Determine the sample size

4. Analyze the data obtained

5. Present research results

The point of these steps is to make the marketing research plan work well with the goal of making winning decisions, both at the strategic and operational levels.

This process is so important and significant for every market participant that it can be said that there is no business in front of market research.

${ }^{21}$ JPMNT, Vol.7, No 2, 2019. Stošić Mihajlović, Lj., Trajković, S., Agressive vs. discrete marketing, pp.7 


\section{TOOLS IN MARKET RESEARCH}

Contemporary business practices have many, mostly, completely free tools available to help you reach important planning, development and management information for your business.

The basic rule is that before any product is put into production, it is necessary to test the market demand beforehand in order to get the first feedback from the target market segment. This involves serious and complex research so it is even expensive for beginners in business and entrepreneurs. It also takes time to come up with the necessary information for business decision making.

However, the development of the Internet and ICT has led to the availability of powerful tools today, at no cost, to sole proprietors in their individual research. It should be noted that the proper use of market research tools involves the order of activities:

1. Defining research problems,

2. Approach to research problem,

3. Design (design) of research,

4. Collection and evaluation of data,

5. Data preparation and analysis,

6. Preparation of the report,

\section{Presentation.}

In all these stages, however, it is necessary to have some experience. Also, it is important to know that secondary data sources are widely available, less expensive, and therefore less applicable to a specific example.

\section{MARKET RESEARCH PLAN AND PROCEDURE}

Before conducting any market research, an analysis of the current situation should be made, which is the first and basic prerequisite for developing a quality marketing plan. The aim of the current situation is to identify and describe customers or users of services, to identify existing and potential competitors, to take into account the business of the company, the price level and to analyze some of the financial characteristics of the company.

Information gathering reduces risk when making business decisions.

Useful information in market research can be:

- purchasing power of potential buyers

- the way a potential buyer makes a purchase decision

- how well the potential customer and customer understands the advantages and / or disadvantages of the product

- actual demand for a particular product

- price and conditions of sale of the product

- intellectual property conditions

- standards and legislation.

After collecting useful information, it should be analyzed, processed and adequately interpreted to obtain information in a form that is appropriate for business decision-making. The information may contain both the advantages and disadvantages of having a planned business. 
This step is especially important because it gives you real ideas about the product and the problems we will encounter in the process of implementing the business plan.

\section{CONCLUSION}

It takes a business idea to start every business. Ideas are said to drive the world and make it a better place for people to live. The idea is also the key to business success, but it must be strictly realistic, achievable and achievable.

Steps in market research can greatly contribute to creating a balanced, realistic and workable business idea. It is mandatory that a business plan containing all the necessary analyzes regarding market trends should be drawn up before starting any new business venture. A business plan is a powerful analytical tool that guides an entrepreneur through an uncertain future, burdened with numerous problems and impacts, both internal and external.

\section{LITERATURE}

Levin, M. [2012]. Gerila PR 2.0, Laguna, Beograd MCLUHAN, M. [1967]. The Medium is the Massage: An Inventory of Effects, Penguin Books, London

Vukotić, S., Aničić, J., \& Vukotić, R. [2017]. The importance of consulting in contemporary business management. Journal of Process Management. New Technologies , 5(3), 69-78.

Stošić-Mihajlović, L., \& Trajković, S. [2019]. Aggressive vs. discrete marketing. Journal of Process Management. New Technologies, 7(2), 712. http://inkubator.biz/alati-za-istrazivanje-trzistaprvi-korak-za-testiranje-vase-ideje/

https://www.markething.hr/proces-istrazivanjatrzista-i-zasto-je-vazan/

https://deli.rs/blog/5-kljucnih-koraka-uistrazivanju-trzista/ 